\title{
Motorized spiral enteroscopy - when things happen: troubleshooting spiral disconnection at 90 minutes into the enteroscopic procedure
}

In patients with a biliodigestive anastomosis after pancreatic head resection, biliary strictures are a common complication that carry the risk of stone impaction, pain, and cholangitis. Altered anatomy poses a significant challenge for endoscopists, and often standard endoscopic equipment is not adequate to the task $[1,2]$. In the case where there is an extended pancreaticobiliary limb, motorized spiral enteroscopy (MSE) can be used to reach the biliodigestive anastomosis. This procedure, however, requires skilled and well-trained endoscopists, and further anesthesia with orotracheal intubation is mandatory $[3,4]$.

We report the first case of disconnection of a spiral overtube, which occurred in a 73-year-old woman after Whipple procedure and Braun anastomosis. MSE was being performed because of biliary stones, pain, and cholestasis (-Fig.1). At 90 minutes into the intervention, during intubation of the pancreaticobiliary limb, the spiral became disconnected in the distal esophagus. The endoscope was promptly removed and a 20-mm pyloric dilation balloon inserted ( $\vee$ Video 1 ). With the balloon positioned and insufflated, the gastroscope was rotated outside of the patient anticlockwise with gentle traction, thus transferring the movement to the balloon and the spiral for mobilization into the hypopharynx. At this point, the endoscope connector had to be unplugged because of the curling of the umbilical cable. Final recovery of the spiral out of the patient therefore had to be done under fluoroscopic vision during further rotation. During the subsequent gastroscopy, extensive lacerations of the esophagus were found. A gastric tube was placed to reduce further pressure on the esophageal wall. After 2 days of follow-up the tube could be removed and enteral feeding was started and well tolerated. The patient was discharged without any last-

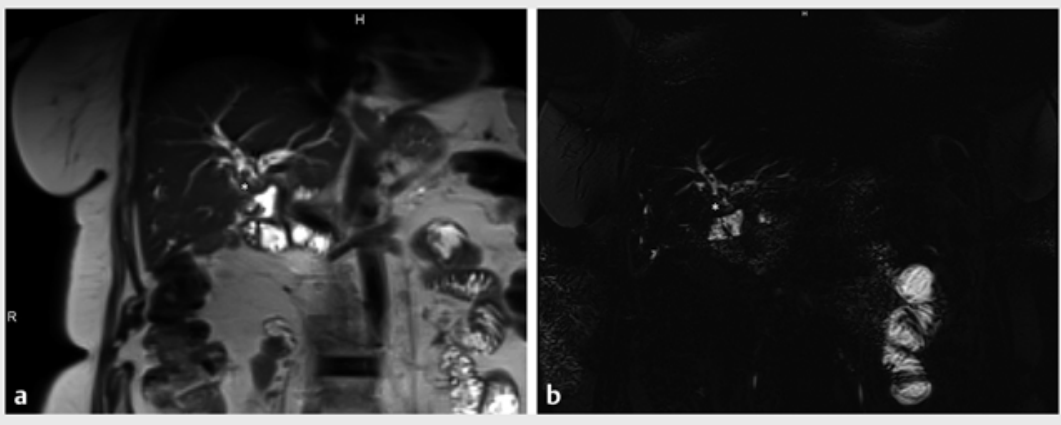

- Fig. 1 a, b Magnetic resonance cholangiopancreatography showing biliary stones retained at the biliodigestive anastomosis $\left({ }^{*}\right)$ after Whipple procedure and Braun anastomosis in a 73-year-old patient.

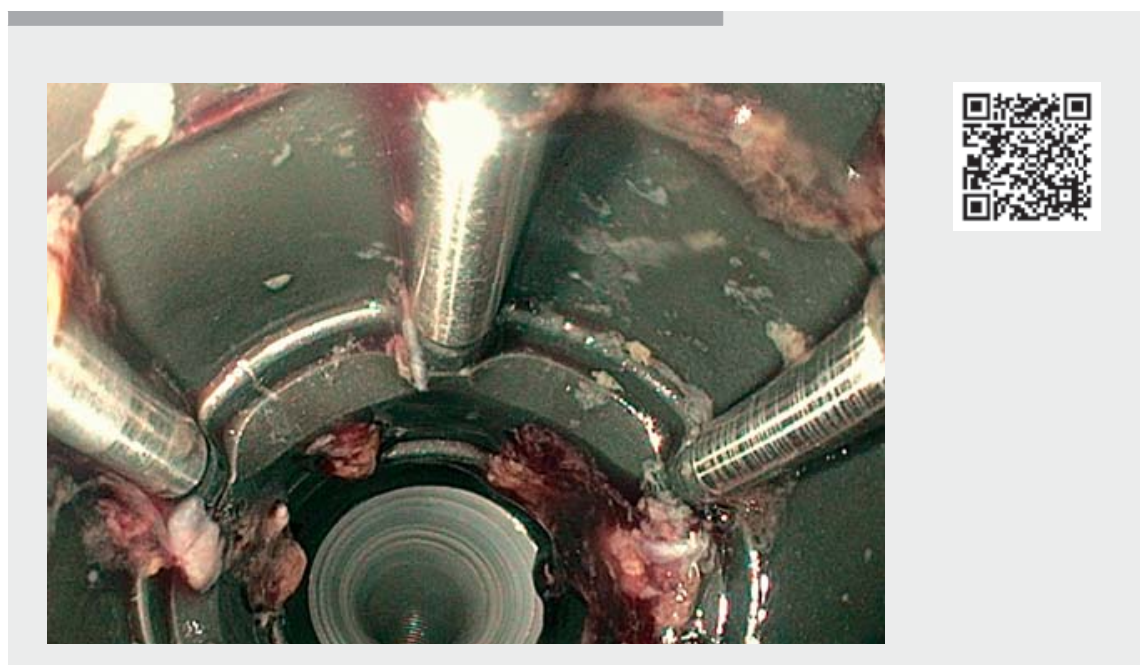

$\checkmark$ Video 1 Recovery of a disconnected spiral overtube in the distal esophagus via balloon extraction during motorized spiral enteroscopy.

ing impairment and received an early reappointment for MSE.

If upper gastrointestinal spiral disconnection occurs, an attempt at salvage can be made utilizing balloon extraction combined with anticlockwise rotation and gentle traction to recover the spiral. If successful, this can prevent the need for surgical intervention.

Endoscopy_UCTN_Code_CPL_1AI_2AC
Competing interests

The authors declare that they have no conflict of interest. 
Emanuel Steiner, Andreas Mayer, Andreas Maieron $(8)$

Internal Medicine 2, Gastroenterology and Hepatology and Rheumatology, Karl Landsteiner University of Health Sciences, University

Hospital of St. Pölten, St. Pölten, Austria

Corresponding author

Andreas Maieron, MD

Department of Gastroenterology and Hepatology, Internal Medicine II, University Hospital St. Pölten, Mühlweg, 3100 St. Pölten, Austria

Andreas.Maieron@stpoelten.Iknoe.at
[1] Moreels TG. Altered anatomy: enteroscopy and ERCP procedure. Best Pract Res Clin Gastroenterol 2012; 26: 347-357

[2] Wu WG, Gu J, Zhang WJ et al. ERCP for patients who have undergone Billroth II gastroenterostomy and Braun anastomosis. World J Gastroenterol 2014; 20: 607-610

[3] Ali MF, Modayil R, Gurram KC et al. Spiral enteroscopy-assisted ERCP in bariatriclength Roux-en-Y anatomy: a large singlecenter series and review of the literature (with video). Gastrointest Endosc 2018; 87: 1241-1247

[4] Shah RJ, Smolkin M, Yen R et al. A multicenter, US experience of single-balloon, doubleballoon, and rotational overtube-assisted enteroscopy ERCP in patients with surgically altered pancreaticobiliary anatomy (with video). Gastrointest Endosc 2013; 77: 593600
Bibliography

Endoscopy 2022; 54: E366-E367

DOI 10.1055/a-1532-1639

ISSN 0013-726X

published online 9.8.2021

(c) 2021. Thieme. All rights reserved.

Georg Thieme Verlag KG, Rüdigerstraße 14 , 70469 Stuttgart, Germany

\section{ENDOSCOPY E-VIDEOS}

https://eref.thieme.de/e-videos

Endoscopy E-Videos is an open access online section, 回神: reporting on interesting cases and new techniques in gastroenterological endoscopy. All papers include a high quality video and all contributions are freely accessible online. Processing charges apply (currently EUR 375), discounts and wavers acc. to HINARI are available.

This section has its own submission website at

https://mc.manuscriptcentral.com/e-videos 